SCIENTIA ET PRAXIS 


\section{Aporte del Movimiento Moderno en la construcción de un nuevo perfil urbano para la arquitectura residencial limeña de 1945 a 1965}

Inés Campos García-Calderón
Doraliza Olivera Mendoza

Universidad de Lima, Perú

Recibido: 6 de septiembre del 2016 / Aprobado: 21 de diciembre del 2016

El Movimiento Moderno en el Perú se manifestó entre 1945 y 1965, periodo en el que arquitectos peruanos que habían estudiado en el extranjero y arquitectos extranjeros que llegaron al Perú ejercieron su profesión influenciados por la nueva arquitectura del siglo xx, resultado de vanguardias europeas como la Bauhaus y De Stijl, el Congreso Internacional de Arquitectura Moderna (CIAM) y la influencia de quienes realizaron su propia arquitectura. El Movimiento Moderno constituyó un gran aporte a la arquitectura limeña. El artículo pretende identificar, a partir de una selección de casos emblemáticos, cómo los elementos de las fachadas diseñadas por los arquitectos modernos del Perú influyeron en la construcción de un nuevo perfil urbano de la arquitectura residencial limeña.

Movimiento Moderno, arquitectura moderna, Movimiento Moderno peruano, perfil urbano, arquitectura residencial limeña

\section{Contribution of Modern Movement to the Construction of a New Urban Profile for Residential Architecture in Lima from 1945 to 1965}

Modern Movement in Peru is comprised between 1945 and 1965. At that time, the Peruvian architects who studied abroad returned to the country as well as the foreigners who arrived to Peru and carried out their profession heavily influenced by the new architecture of the twentieth century - a result from European vanguards such as Bauhaus and De Stijl —, by movements emerged in other countries, by the International Congresses of Modern Architecture (CIAM), and by those who developed their own architecture. The Modern Movement promoted an important contribution to Lima architecture. By selecting symbolic cases, this article tries to identify the way elements in the facades designed by the modern architects of Peru contributed to the construction of a new urban profile in Lima residential architecture.

Modern Movement, modern architecture, Modern Movement in Peru, urban profile, residential architecture in Lima 


\section{INTRODUCCIÓN}

La ciudad es el resultado de las características de los objetos arquitectónicos que se emplazan en ella. La presencia unitaria y el conjunto de las edificaciones crean perfiles urbanos influenciados por los diferentes estilos a lo largo de la historia. Entre 1945 y 1965, el Movimiento Moderno en Lima incorporó en la vivienda un nuevo lenguaje arquitectónico, resultado de la influencia de la arquitectura moderna internacional. Ese lenguaje se enriquece con la introducción de formas, composición, organización, detalles, texturas, nuevos materiales, etcétera. En el presente artículo no se pretende agotar todas las variables de estudio sobre el tema, sino resolver una parte del cuestionamiento sobre la identificación de elementos del Movimiento Moderno internacional en las fachadas de las viviendas de la arquitectura moderna en Lima. La producción arquitectónica del Movimiento Moderno en Lima es vasta, su presencia introdujo elementos que dieron lugar a un nuevo lenguaje arquitectónico que se verá reproducido por los distintos barrios de la ciudad a partir de la expansión urbana. Es por eso por lo que para este trabajo, la investigación del espacio interior es irrelevante. Nos centramos solo en la evaluación de la fachada, lo cual no quiere decir que no se reconozca el valor de la construcción de un espacio interior moderno.

El estudio se centrará en la evaluación de cuatro casos: la Casa Wiracocha y la Casa D'Onofrio, consideradas importantes porque reflejan, por un lado, los primeros intentos por introducir un lenguaje nuevo y, por otro, porque se las reconoce como los elementos representativos del Movimiento Moderno producidos por arquitectos peruanos. En cuanto a la producción de arquitectos internacionales, analizaremos la Casa Alter, de Walter Weberhofer, y el edificio de departamentos de la calle Roma, de Teodoro Cron. Con el estudio se ha encontrado influencia de la Bauhaus, Frank LloydWright, Le Corbusier, De Stijl y Alvar Aalto, evidenciadas en el tipo de emplazamiento, forma, relación con el exterior, lenguaje, estructura, detalles arquitectónicos que crean una unidad que tendrán un impacto en el perfil urbano de la ciudad.

\section{ANTECEDENTES: LA ARQUITECTURA MODERNA INTERNACIONAL}

La Revolución Industrial de 1760, la introducción de nuevas tecnologías y materiales, la ruptura con el pasado historicista y la nueva forma de hacer arquitectura sustentan lo que conocemos hoy como el Movimiento Moderno. Durante la última década del siglo XIX con el denominado art nouveau hasta el periodo interbellum ${ }^{1}$, que concluye en 1940, surgieron en Europa diversos movimientos vanguardistas que influyeron en las artes y en la arquitectura internacional. En los Países Bajos (1917-1932), por ejemplo, aparecieron De Stijl, Theo van Doesburg, Piet Mondrian, Gerrit Rietveld, entre otros. El primer manifiesto (1918) expresaba que todas las artes debían de integrarse para lograr una expresión colectiva y universal que superara el individualismo. Planteaba, además, la simplificación de los materiales y el uso de pautas elementales de diseño: la luz, la función, el volumen, el tiempo, el espacio, los colores primarios (a los que se sumaron el gris, el negro y el blanco), la geometría elemental, la

1 Se le llama así al periodo entre guerras. 
línea recta, los planos horizontales y verticales infinitos y la ortogonalidad, conceptos presentes en la Rietveld-Schöerderhuis (García, 2010) (figura 1).

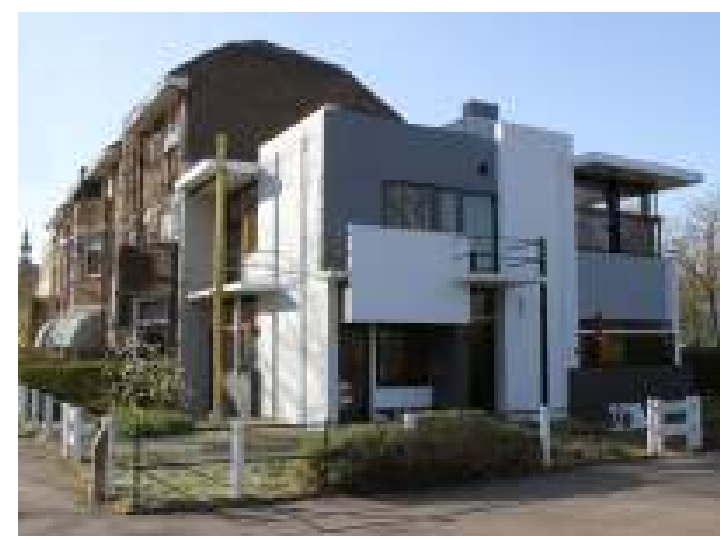

Figura 1

Casa Rietveld-Schöerderhuis, 1924, Rietveld, Utrecht, Países Bajos Fuente: http://trenchantiques.blogspot.pe/2011/02/piet-mondrianand-de-stij..html

García y Frampton (2010 y 2003), entre otros autores, sostienen que en De Stijl se encuentra la influencia de Frank Lloyd Wright mediante sus publicaciones alemanas de 1910 a 1911, las conferencias de Hendrik Petrus Berlage ${ }^{2}$ y los diseños de J.Wils que recuperan elementos del lenguaje arquitectónico de las casas de la pradera (figura 2). Wright, utilizó tres conceptos: la casa de la pradera, la arquitectura usoniana y la arquitectura orgánica. Los dos primeros están vinculados a la horizontalidad del terreno, las proporciones de techos bajos, la fluidez

2 Arquitecto holandés de influencia en el desarrollo de la arquitectura moderna en los Países Bajos, a finales del siglo xIx e inicios del xx. del espacio unitario interior, dividido con la chimenea y la expansión de la vivienda sobre el terreno, el tratamiento paisajístico y la conexión entre el espacio interior y el exterior, lo que genera armonía entre naturaleza y arquitectura. La diferencia entre ambos conceptos es que en el usoniano, dirigido al sector de clase media, la planta es el reflejo de la función. En cuanto al orgánico, la edificación se adapta al medio natural (figura 3).

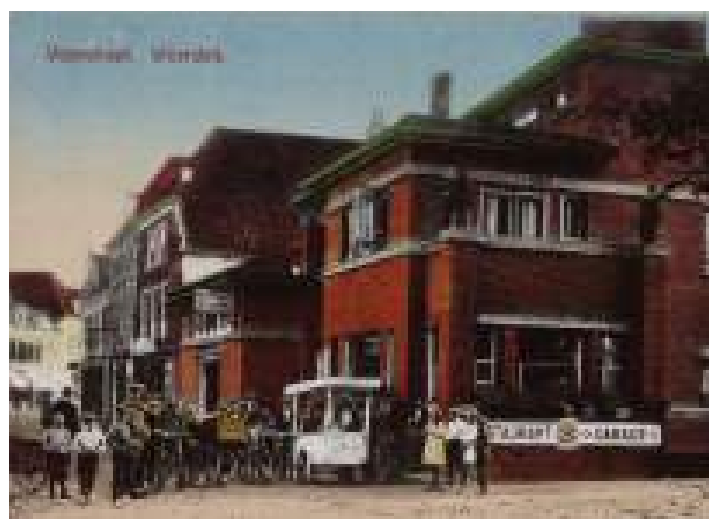

Figura 2

Hotel De Dubbele Sleutel, 1918, Wils, Woerden, Países Bajos Fuente: https://www. pinterest.com/pin/459367230724370234/ visual-search/? $x=0 \& y=0 \& w=459 \& h=334$

El planteamiento original de fusión entre arte y artesanía como unidad de trabajo en la construcción de un edificio de la escuela Bauhaus (Alemania 1919-1933) fue cambiando hacia al arte espacial. La escultura, la pintura y la arquitectura juntas eran herramientas utilizadas para la reforma de la enseñanza de las artes aplicadas. Walter Gropius planteó la construcción como producto del trabajo colectivo, las reglas de composición espacial regidas por la intuición y las matemáticas, el intercambio entre individuo y cosmos y la decoración interior y exterior. 


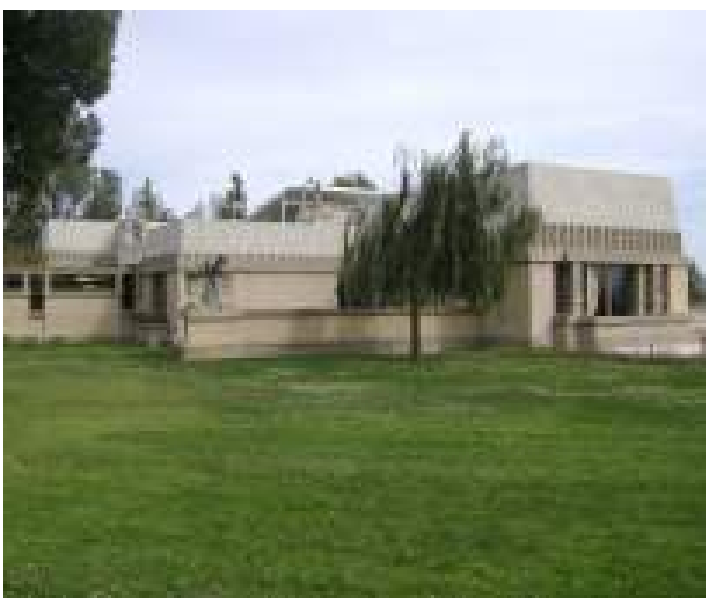

Figura 3

Hollyhock House, 1919-1921, Wright, Los Ángeles, EE. UU. Fotografía: Inés Campos

La escuela Bauhaus, en su sección de arquitectura, pasó por cinco etapas. La primera fue en 1921, cuando Doesburg imparte un curso sobre De Stijl, en el que busca un lenguaje común de formas y colores como medio de comunicación universal. La segunda, en 1922; Gropius plantea arte y técnica como una nueva unidad de trabajo, la Bauhaus se vuelve más productiva y se inserta en la era de la industrialización. La tercera, de 1925 a 1927, cuando se utilizan como ejes comunes de diseño la sinceridad de materiales, los elementos estandarizados, las líneas rectas, los ángulos de $90^{\circ}$, los techos planos, la separación de las funciones, la visualización del interior, el vínculo entre el exterior y el interior, la luminosidad; se emplean el vidrio y el hierro; se opta por colores primarios, así como por el blanco y el negro (figura 4). Las dos últimas etapas transcurren primero con Hannes Meyer (19271930), cuando impartía clases de funcionalismo, colectivismo y constructivismo, y luego con Mies van der Rohe (1930-1933), con quien se plantean las construcciones planas, se enfatiza en el arte espacial más que en el funcional, en los espacios fluidos, en las proporciones armónicas, en los materiales y mobiliarios selectos, en la armonía entre el espacio libre y sus límites (Droste, 1993) (figura 5).

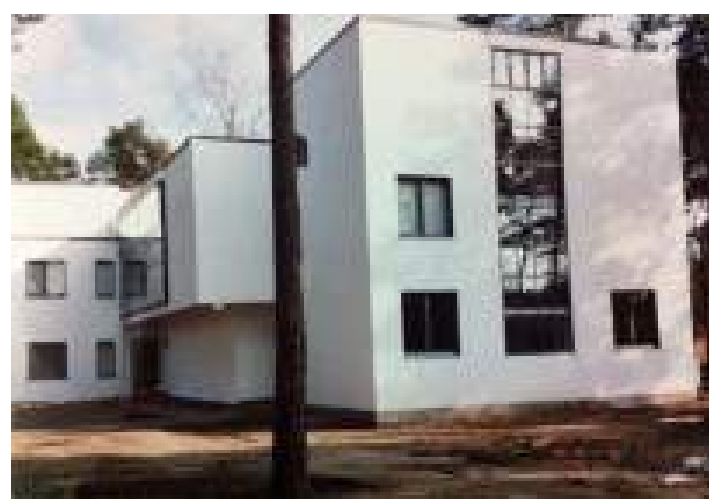

Figura 4

Casas de los Maestros, c. 1925-1927, Gropius y la Escuela Bauhaus, Dessau, Alemania

Fotografía: Doraliza Olivera

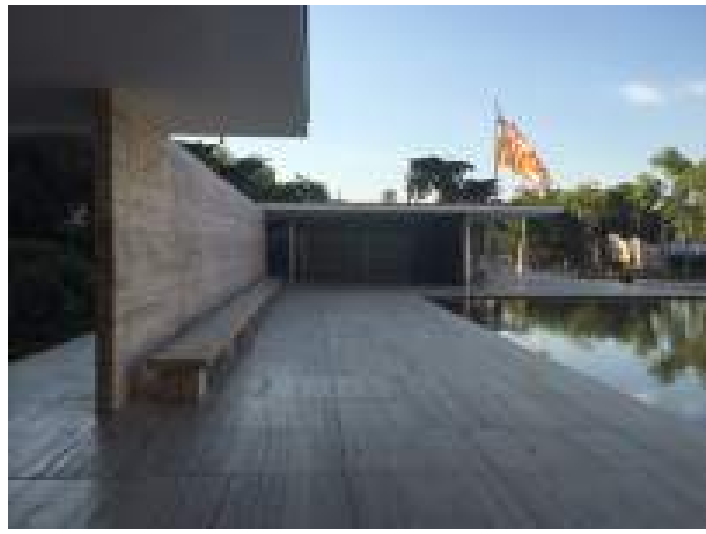

Figura 5

Reconstrucción de 1996: Pabellón Alemán, Exposición Universal de Barcelona, 1928-1929, Mies van der Rohe, Barcelona, España

Fotografía: Daniel Maraví 
En Europa, la arquitectura moderna se desarrollaba de manera homogénea, los profesionales se trasladaban de un país al otro e intercambian información. En 1928 surgieron los Congresos Internacionales de Arquitectura Moderna (CIAM) y fue en el segundo CIAM (1929) cuando Le Corbusier y Pierre Jenneret, con su Villa Savoye en Poissy, plantearon formalmente una arquitectura habitacional que se sustentaba en la aplicación de los cinco puntos de la nueva arquitectura: pilotis, terraza-jardín, planta libre, fachada libre y ventanas corridas, factibles con el uso de concreto reforzado (figura 6). En 1959 surgieron el TEAM X y las propuestas de arquitectos que trabajan de manera individual, como Alvar Aalto en Finlandia quien, entre 1923 y 1976, planteó un nuevo regionalismo con pinceladas de modernidad. La arquitectura, según Aalto, debe adaptarse al paisaje, romper la rigidez del edificio equilibrando líneas, superficies y volúmenes con elementos geométricamente simples colocados de manera oblicua, con más color, riqueza y cordialidad, con materiales del lugar (madera y ladrillo), haciendo de la obra una unidad que integre desde el edificio hasta el accesorio más pequeño. El edificio debe ser un lugar que dé vida sin regirse estrictamente en la grilla del programa (Frampton, 1993).

\section{El CONTEXTO PERUANO: Características DEL MOVIMIENTO MODERNO EN LIMA (1945-1965)}

La etapa del desarrollo urbano de Lima fue el resultado de la aplicación de ideas planteadas desde finales del siglo anterior. Se buscaba la apertura de grandes vías, la modernización de la ciudad y la reconstrucción nacional. Esto se materializó durante el segundo gobierno de Augusto B. Leguía (1919-1930), con quien se ingresó a una nueva etapa de modernización del

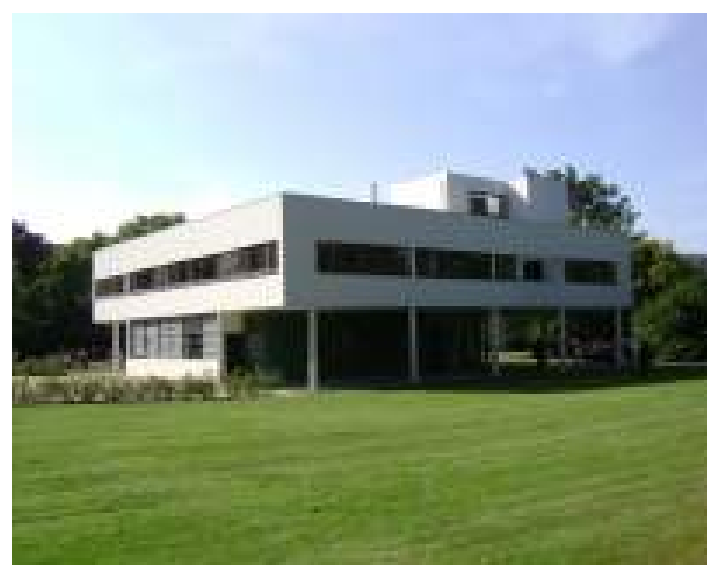

Figura 6

Villa Savoye (1928-1929), Le Corbusier y Pierre Jenneret, Poissy, Francia

Fotografía: Inés Campos

país mediante el desarrollo de una cultura urbana en busca del que buscaba el cosmopolitismo, lo que dio lugar a la ciudad de suburbio con viviendas tipo chalet y de estilo pintoresquista (Ludeña, 2002).

Hacia 1940, algunos eventos produjeron cambios en la arquitectura y el urbanismo. Lima empezó un proceso de crecimiento acelerado y desordenado, con escasez de espacios públicos y de infraestructura de servicios, un incremento poblacional que ocasionó el hacinamiento y la tugurización de viviendas. En mayo de 1940, la zona costera de Lima y Callao fue azotada por un terremoto que ocasionó el derrumbe de viviendas y que, sin embargo, sirvió de motivación para iniciar una campaña que sirviera para solucionar el problema habitacional.

Los referentes para cambiar la arquitectura de la época eran los nuevos materiales de construcción, las revistas y los documentos internacionales sobre arquitectura moderna de Le Corbusier y 
Gropius. HéctorVelarde, en su libro Arquitectura peruana (1946), introduce nuevas imágenes urbanas con diferentes estilos de viviendas obtenidas del cine (Martuccelli, 2000). Fernando Belaunde fundó la revista El Arquitecto Peruano (1937-1963); Luis Miró Quesada publicó su Espacio en el tiempo (1945); se celebró el VI Congreso Panamericano de Arquitectura (1947), cuyo debate se centró en hacer frente a la dependencia cultural y la búsqueda de identidad de la arquitectura latinoamericana (Universidad de Lima, 2016). Un grupo de arquitectos y artistas modernos firmaron el manifiesto de la Agrupación Espacio (1947) con el cual asumían la defensa de Lima y su arquitectura; sostenían que la arquitectura moderna al coexistir con la tradicional no producía desarmonía; vinculaban el arte del presente con el del pasado y resaltaban la incapacidad de la arquitectura neocolonial por no integrarse al paisaje urbano barroco.

En 1946, el entorno académico del Departamento de Arquitectura de la Escuela de Ingeniería (actualmente la UNI) fue influenciado por las ideas de la arquitectura moderna, cimentadas con la participación y las visitas de arquitectos extranjeros como Mario Bianco, Paul Linder y, posteriormente, Gropius y Josep Lluís Sert. En 1951, Belaunde lideró la construcción del actual edificio proyectado por Bianco.

En 1949, los urbanistas Sert, Paul Lester Wiener y Ernest Rogers plantearon el Plan Piloto de Lima y tuvo como referencia las ideas de modernidad de Le Corbusier, fue planteado por los urbanistas Sert, Paul Lester Wiener y Ernest Rogers. Según Ludeña (2002), para el plan, el centro histórico debía ser reemplazado con una nueva ciudad de bloques con pilotis y ventanas corridas ${ }^{3}$. Durante el gobierno de Manuel A. Odría (1948-1956), se continuó con la política de construcción de vivienda popular para obreros y empleados en todo el país y se desarrolló la arquitectura del Movimiento Moderno introducida en el país desde 1940, pero, al tratarse de una condición importada, no respetaba las características del contexto, del entorno ni de las necesidades del usuario según sus patrones socioculturales.

\section{EL PERFIL URBANO Y LA ARQUITECTURA EN LIMA A MEDIADOS DEL SIGLO XX}

Hasta 1930 el estilo arquitectónico predominante tenía influencia beaux arts por su academicismo e historicismo, cuyos representantes desde finales del siglo XIX fueron Ricardo Malachowski, Claudio Sahut y Enrique Bianchi. Un ejemplo es el estilo palaciego francés del edificio Rímac o Casa Roosevelt (1919-1924), de Malachowski. Con el crecimiento de la ciudad hacia el sur, las viviendas de los balnearios se transformaron en viviendas tipo villa o chalet. Se promovió una estética pintoresquista, ecléctica y el desarrollo de revivals en la arquitectura, que hacían convivir en la ciudad diferentes estilos: tudor, art déco, chalets neocoloniales y neoincas. Esta situación generó una reacción que buscó recordar el pasado hispano con el estilo neocolonial; rescatar las culturas precolombinas con el indigenismo y fusionarlos, a fin de promover un mestizaje cultural con el estilo neoperuano (Martuccelli, 2000).

3 El Plan Voisin de Le Corbusier sirvió de referencia para el planteamiento del Plan Piloto de Lima, con él se apostaba por una ciudad con otro paisaje urbano, erradicando los balcones de cajón que desde finales del siglo xIx significaron problemas de higiene urbana. (Ludeña, 2002) 
Hacia 1919 Manuel Piqueras recogió valores hispanos y nativos en la representación del pabellón peruano de la Exposición de Sevilla. En el Hotel Country Club de San Isidro (1929), se emplearon elementos decorativos inspirados en el plateresco, barroco español; detalles que fueron introducidos en el tratamiento decorativo de las viviendas de los años treinta. En algunas viviendas se recurrió a los techos a dos aguas cubiertos de tejas al estilo californiano, que evocaba el estilo vernacular de las casas de adobe de la sierra peruana, publicadas en El Arquitecto Peruano.

La arquitectura neocolonial se caracterizó por ser maciza, de escala monumental, con tendencia a la horizontalidad, con un eje principal definido por un ingreso jerarquizado con un pórtico de detalles ornamentales, arcos de medio punto, molduras y elementos decorativos heredados del espíritu de la colonia, como se muestra en la fachada del nuevo Palacio Arzobispal de Lima, de Malachowski. Los últimos representantes del neocolonialismo fueron Enrique Seoane y Alejandro Alva, cuyas viviendas eran "volúmenes compactos, densos, la irregularidad en la ubicación y tamaño de los vanos y la intensificación un poco impresionista de la plasticidad de las portadas, molduras y contrafuertes" (García, 1980, p. 146), los edificios de departamentos presentaban "la minimización o abandono de la simetría y del balance académico, [...], así como la subordinación de motivos de inspiración colonial aislados y estilizados (portadas, arquerías) a un contexto arquitectónico contemporáneo..." (García, 1980, pp. 146-147). La presencia de este estilo se reforzaba con textos como los de Velarde y ordenanzas municipales que exigían su aplicación en la construcción de las edificaciones en el Centro Histórico de Lima.
El estilo neoincaico-indigenista tomó valores de la cultura prehispánica, lo cual generó volúmenes con techos inclinados al estilo de las viviendas andinas. El estilo art déco (figura 7) influyó en la decoración interior al plantear distintos tipos de objetos de uso doméstico, artefactos, y logró integrar el interior, el exterior y el mobiliario, tal como lo había hecho el art nouveau, constituyendo un momento de transición entre los estilos académicos y la arquitectura racionalista y funcionalista que se estaba desarrollando bajo la influencia de los rascacielos norteamericanos (García, 1980).

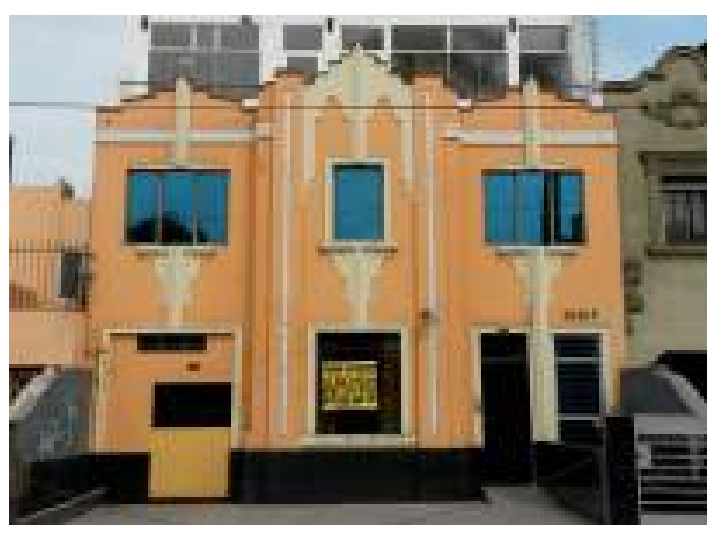

Figura 7

Casa estilo art déco, autor desconocido, avenida Arequipa, Lima, Perú

Fotografía: José Luis Vértiz

Por otro lado, el estilo buque (figura 8), derivación de la arquitectura racionalista, se manifestó con la presencia de materiales modernos (vidrio, cromo), sin hacer énfasis en la decoración, con una composición volumétrica asimétrica y dinámica, con su empleo de formas geométricas puras, juego de vanos y volados que volteaban sobre el volumen y el uso de un vano circular llamado ojo de buey, barandas de hierro, horizontalidad y 
simplicidad. Este estilo fue empleado en quintas y casas tipo chalet ubicadas en distritos como Miraflores, San Isidro, La Punta y en algunos casos se combinaban con pinceladas de art déco y racionalismo.

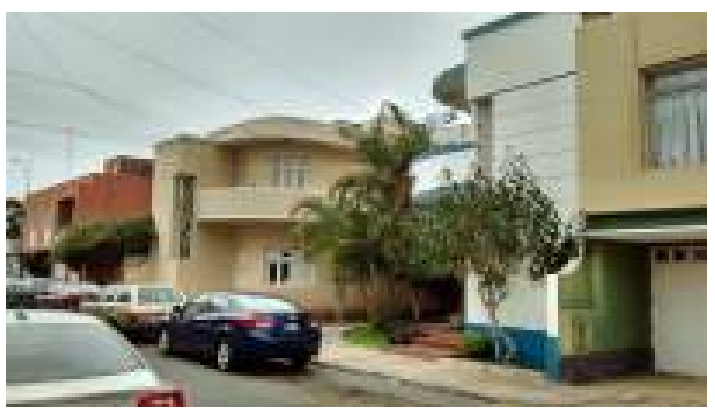

Figura 8

Casa estilo buque, autor desconocido, avenida More, La Punta, Callao, Perú

Fotografía: Inés Campos

Hacia 1945 los principios de la arquitectura moderna internacional fueron plasmados en la arquitectura residencial peruana, donde se ve el aporte en las fachadas, lo que generó cambios en las características del perfil urbano, como se ve en las obras Casa Wiracocha, de Luis Miró Quesada (1948) (figura 9); Casa D'Onofrio, de Carlos Williams, Mario Bianco y Adolfo Córdova (1949) (figura 10); el edificio de departamentos en la calle Roma, de Teodoro Cron (1950) (figura 11), y la Casa Alter, de Walter Weberhofer (1956) (figura 12).

Analizando las obras a partir de su emplazamiento se definen las viviendas como volúmenes horizontales compactos, a diferencia de la Casa D'Onofrio en donde el volumen se extiende sobre el terreno al estilo de las casas de la pradera, de Wright.

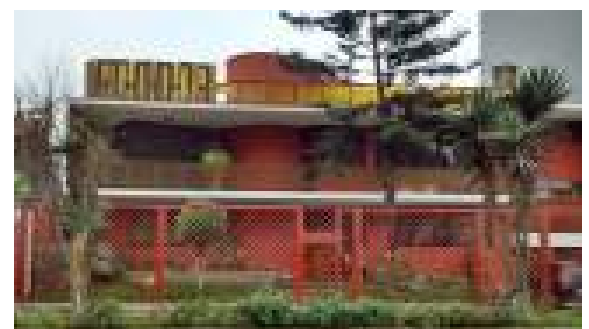

Figura 9

Casa Wiracocha, de Miró Quesada (1948), avenida Wiracocha, Jesús María, Lima, Perú Fotografía: Inés Campos

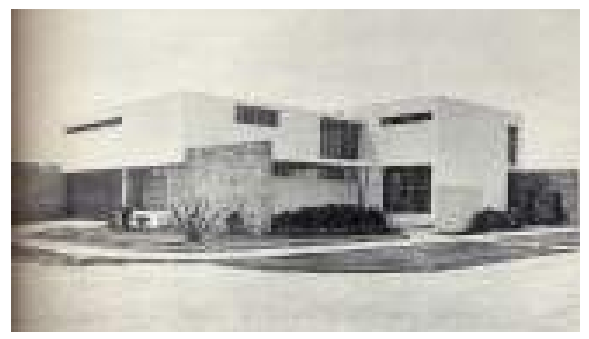

Figura 10

Casa D’Onofrio, de Bianco, Córdova y Williams (1949), demolida, Lima, Perú

Fuente: El Arquitecto Peruano, 1950

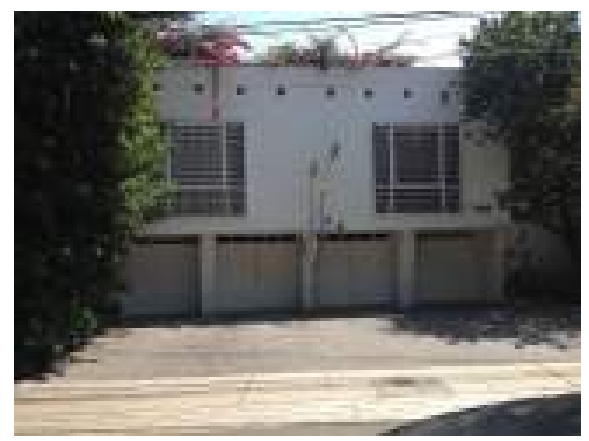

Figura 11

Edificio de departamentos de la calle Roma, de Cron (1950), San Isidro, Lima, Perú

Fotografía: Inés Campos 


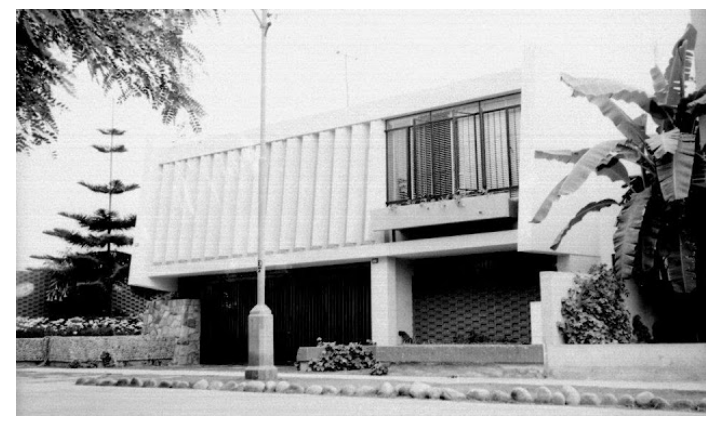

Figura 12

Casa Alter, 1956, de Weberhofer, demolida, Magdalena, Lima, Perú Fuente: El Arquitecto Peruano, 1950

En cuanto a la direccionalidad, esta es principalmente horizontal; a diferencia de la Casa Wiracocha, rompe con un volumen cilíndrico que recuerda a Le Corbusier (figura 12). En relación con sus formas, se utiliza una geometría elemental planteada por De Stijl como rectángulos y cuadrados; también se encuentran aportes locales con formas trapezoidales, estas últimas en la Casa Alter y en el edificio de Cron (figura 13). A partir de De Stijl, se toma también la idea de los planos horizontales y verticales infinitos que se aprecian tanto en la Casa Alter (figura 14), con los planos que salen de los vanos a manera de tapasol, los planos del cerramiento de la fachada y el plano horizontal de la jardinera. En la Casa D'Onofrio (figura 15), los muros verticales de piedra salen sobre el retiro. Los vanos horizontales, que toman la mayor parte de las fachadas, permiten la lectura de la diferenciación de funciones de los espacios de la vivienda, la conexión interiorexterior, la visualización desde el exterior y la mayor luminosidad del edificio se vinculan a la Bauhaus.

El edificio diseñado por Cron (figura 11) presenta en el segundo piso un volumen horizontal sostenido por contrafuertes trapezoidales y se asemejan visualmente a la idea de los pilotis de Le Corbusier. La Casa Wiracocha enriquece el uso del techo plano a manera de terraza, acompañada con elementos virtuales de cerramiento a manera de remate virtual del último nivel de la fachada al estilo Le Corbusier. Se optó por materiales de uso común en la arquitectura moderna, como el ladrillo, el concreto, el vidrio y el fierro, así como por materiales naturales, como la piedra, sugerido por la arquitectura de Aalto, que mezcla en su lenguaje arquitectónico regionalismo y modernidad, y que es más notorio en la arquitectura de Cron. Los colores usados fueron principalmente el blanco combinado en algunos casos con el gris de los muros y las jardineras de piedra. El común denominador de las viviendas es el diseño unitario que toma en cuenta de manera indivisible el emplazamiento del volumen, las plantas hasta el más mínimo detalle, tal como lo propuso Aalto y que también desarrollara la Bauhaus, Wright y De Stijl. Las fachadas son el resultado de su consideración como una totalidad, en la que no hay ningún elemento que no tenga una razón de ser, lo cual favoreció la composición de piezas que no solo quedaban como elementos decorativos. 

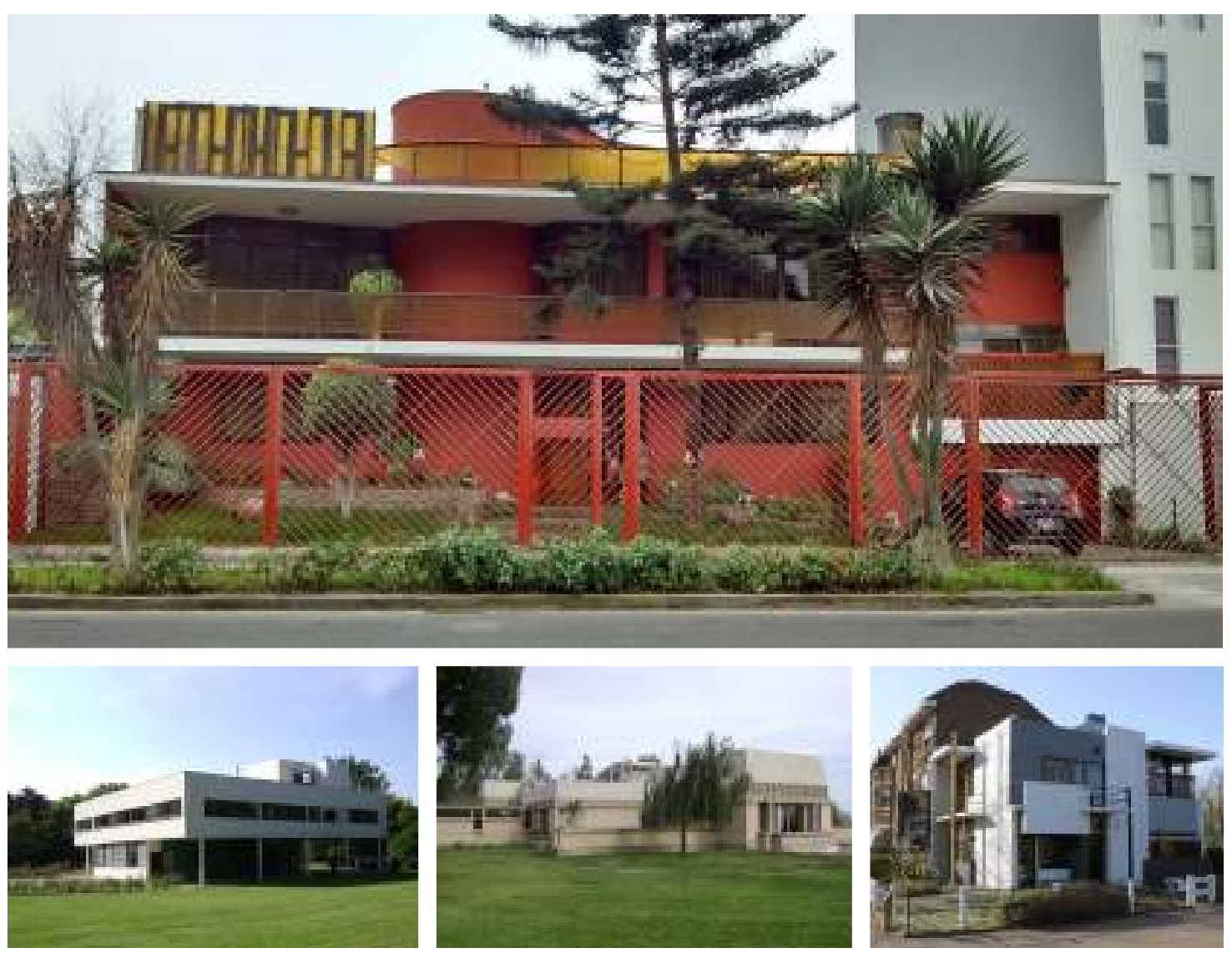

Figura 13

Casa Wiracocha, de Miró Quesada y sus referentes: formas curvas como remate de la edificación. Emplazamiento horizontal, elementos lineales que refuerzan la horizontalidad tanto de Wright como de De Stijl

Fotografías: Inés Campos.

Recuperado de http://frenchantiques.blogspot.pe/2011/02/piet-mondrian-and-de-stijl.html 

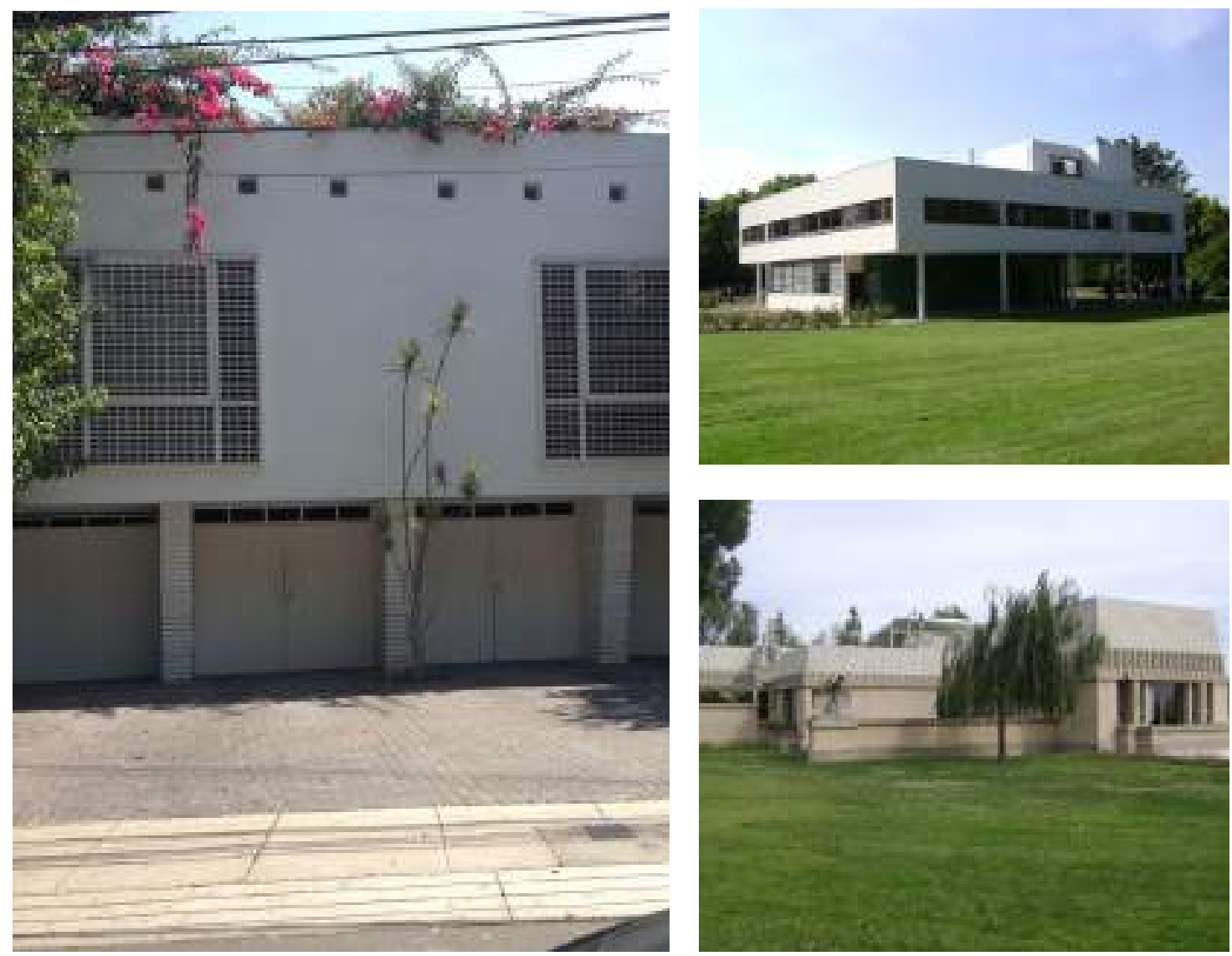

Figura 14

Edificio de departamentos de Teodoro Cron y sus referentes. Le Corbusier (pilotis) y De Stijl (formas básicas rectangulares y cuadradas)

Fotografías: Inés Campos 

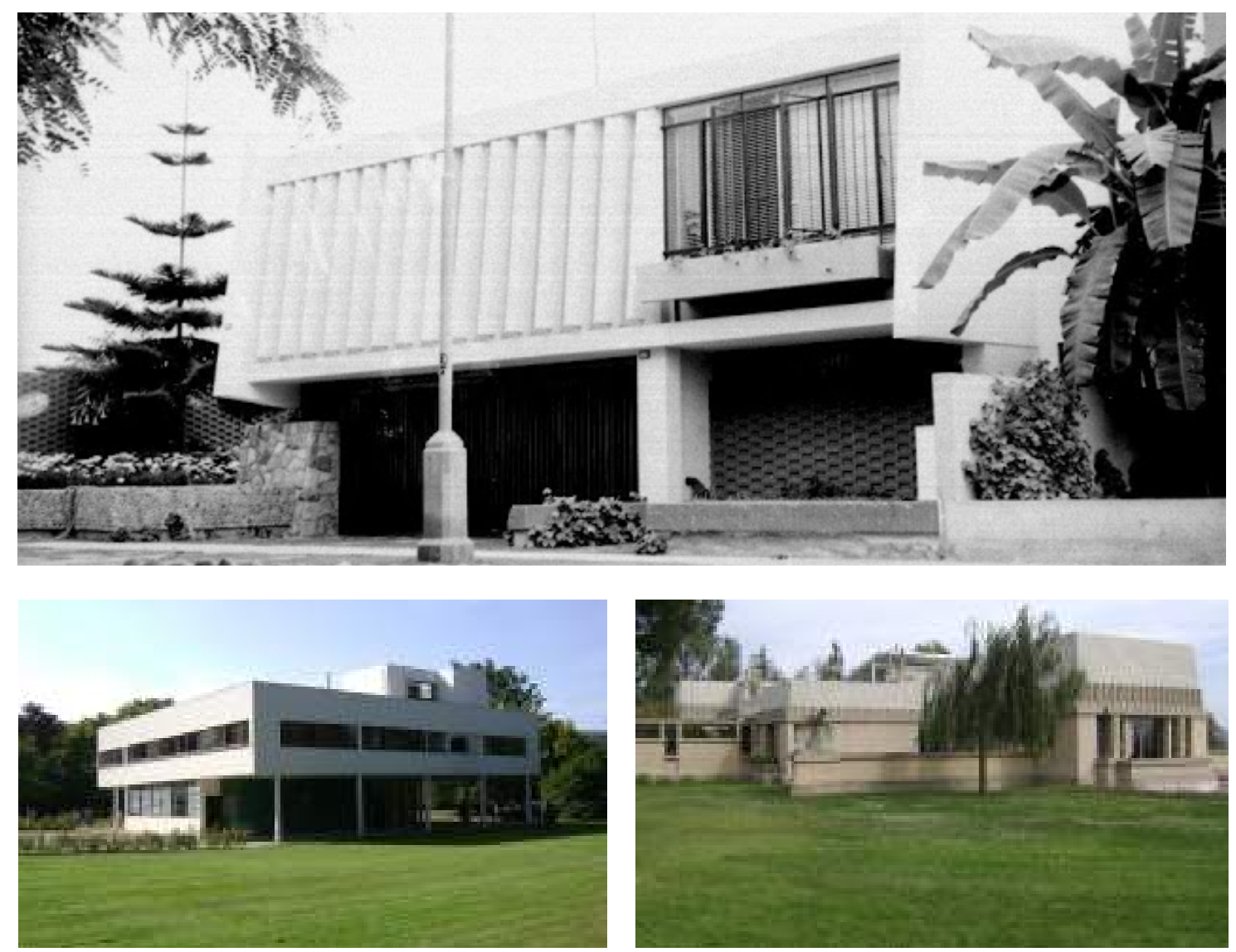

Figura 15

Casa Alter, de Weberhofer y sus referentes. Le Corbusier, volumen suspendido, uso del material y emplazamiento, de Wright Fuente: El Arquitecto Peruano, 1951

Fotografías: Inés Campos 

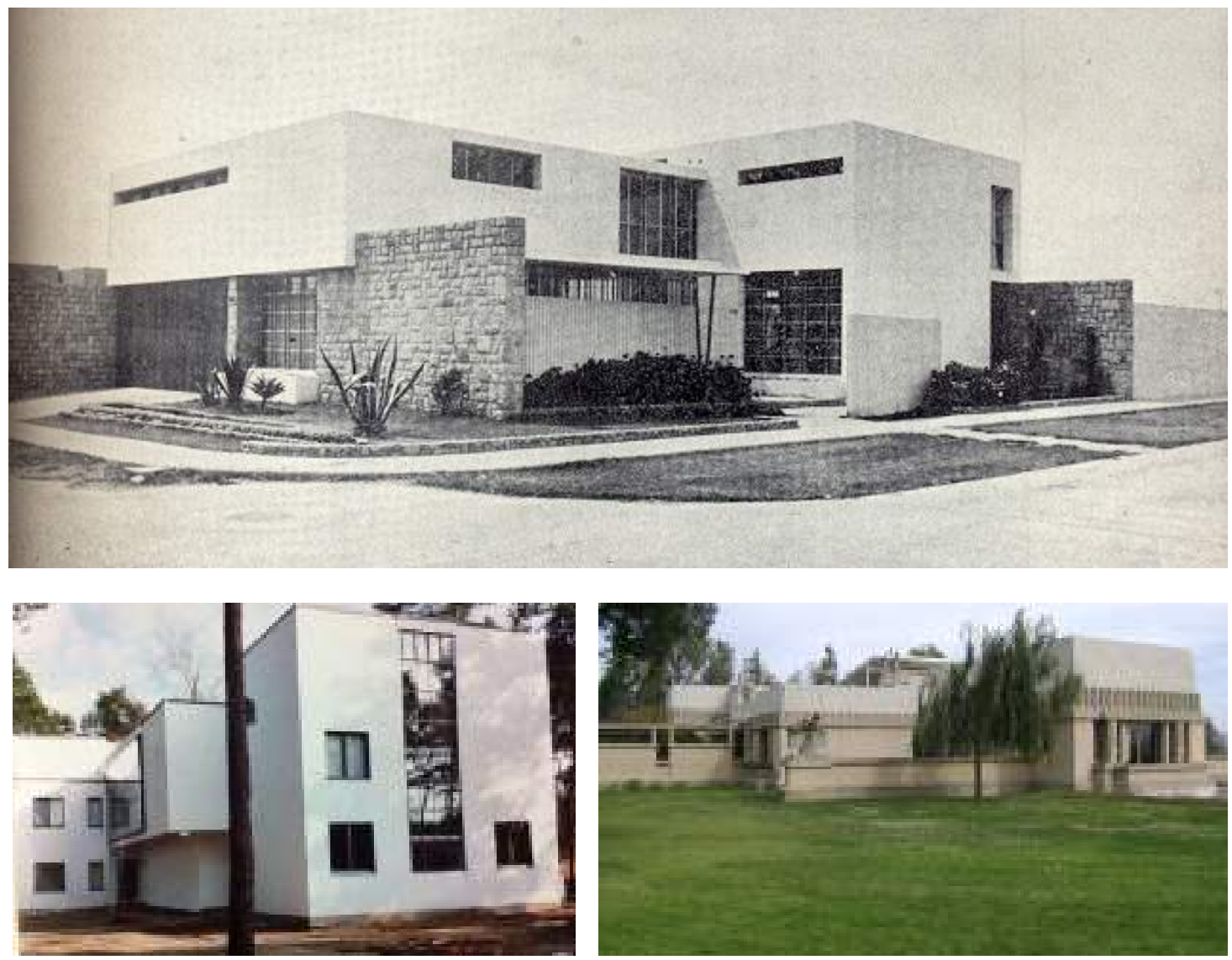

Figura 16

Casa D'Onofrio y sus referentes. Formas cúbicas Bauhaus, relación interior-exterior y emplazamiento Bauhaus-Wight

Fuente: El Arquitecto Peruano, 1950

Fotografías: Doraliza Olivera e Inés Campos 


\section{CONCLUSIONES}

Durante el siglo $\mathrm{xx}$, coexistieron en Lima distintos estilos arquitectónicos, partiendo del academicismo, pasando por distintos estilos hispanos en busca de un estilo propio. Si bien el lenguaje arquitectónico de los detalles coloniales, barrocos y pintoresquistas que se replican en las viviendas de las nuevas urbanizaciones es variado, otorga una imagen continúa al perfil urbano de la ciudad.

La presencia y el desarrollo de la arquitectura moderna en el Perú son el resultado del contexto político, socioeconómico y cultural que facilitó las condiciones para su inserción en la arquitectura residencial limeña. Los conceptos de la arquitectura moderna internacional fueron introducidos y aplicados en el diseño habitacional por arquitectos nacionales y extranjeros que desarrollaron la práctica profesional en la ciudad. Analizando los casos de estudio se puede reconocer la influencia de escuelas y posturas individuales del Movimiento Moderno como la Bauhaus, De Stijl, Wright, Aalto y Le Corbusier.

La inserción de detalles residenciales modernos en la trama urbana introduce un lenguaje nuevo en las fachadas y formas de emplazamiento que transforma el perfil urbano tradicional y su relación con el espacio público.

Entre 1945 y 1965, se apuesta en Lima por una vivienda de fachada horizontal con retiro, lejos de la típica idea de bloque compacto a pie de vereda, que replicada a lo largo de la calle implicaría el incremento del área verde en el espacio público con los jardines y las jardineras de retiro que dan ingreso al estacionamiento. Los volúmenes de proporciones con poca altura logran un perfil horizontal que se rompe muy eventualmente con acentos verticales.
El lenguaje arquitectónico deja de lado el arco de medio punto y opta por formas geométricas puras y elementales, y el uso de planos horizontales y verticales infinitos que prolongan los ejes del volumen hacia el entorno. Se introduce el uso de materiales naturales como equilibrio con productos del desarrollo tecnológico. La arquitectura se entiende como una totalidad donde se trabaja desde el planteamiento inicial hasta el detalle, lo cual genera un perfil urbano con texturas y colores, y crea una composición integral.

A lo largo del tiempo los elementos empleados en el diseño de las fachadas de las viviendas modernas se encuentran en la arquitectura del entorno a través de la réplica de los colores, los vanos, elementos de decoración como jardineras y volados, tratando de generar una continuidad inconsciente.

\section{REFERENCIAS}

Abarca Torres, H., et al. (2016). Walter Weberhofer. El proyecto moderno en el Perú. Lima: Universidad de Lima, Fondo Editorial.

Bauhaus Archiv y Droste, M. (1993). Bauhaus 1919-1933. Berlín: Benedikt Taschen Verlag $\mathrm{GmbH}$.

El Arquitecto Peruano (1950). Residencia del señor Luis D‘Onofrio en Orrantia del Mar. El Arquitecto Peruano,(150-151), 38-44.

El Arquitecto Peruano. (1950). Departamentos en la calle Roma. San Isidro. El Arquitecto Peruano, (153), 25.

Frampton, K. (2003). Modern Architecture, A Critical History (3. ${ }^{a}$ ed.). Londres: Thames $\&$ Hudson, Word of Art. 
García Bryce, J. (2013). Héctor Velarde. Sabiduría con un toque de humor. En R. Gutiérrez, et al. Héctor Velarde. Arquitecto y humanista (pp. 37-54). Lima: Universidad de Lima, Fondo Editorial.

García, R. (2010). Arquitectura moderna en los Países Bajos, 1920-1945. Madrid: Ediciones Akal.

Gutiérrez, R. et al. (2013). Héctor Velarde. Arquitecto y humanista. Lima: Universidad de Lima, Fondo Editorial.

Hart, S. (2004). Frank Lloyd Wright. North Dighton: World Publications Group, Inc.
Ludeña,W.(2002).Lima:poder, centro y centralidad. Del centro nativo al centro neo-liberal. EURE

- Revista Latinoamericana de Estudios Urbanos regionales, 28(83), 45-65.

Martuccelli, E. (2000). Arquitectura para una ciudad fragmentada. Ideas, proyectos $y$ edificios en la Lima del siglo XX. Lima: Universidad Ricardo Palma.

Tamayo, A. (2010). Arquitectura de Lima. 1910-1950. Lima: Cecosami Pre Prensa e Impresión Digital.

Toca, A. (1990). Nueva arquitectura en América Latina: presente y futuro. México, D. F: Editorial Gustavo Gili. 
